ABDI: Jurnal Pengabdian dan Pemberdayaan Masyarakat ISSN: 2656-369X (Print), 2684-8570 (Online)

Volume 3 No. 2, Desember 2021

http://abdi.ppj.unp.ac.id/index.php/abdi

Email: abdi@ppj.unp.ac.id

DOI: https://doi.org/10.24036/abdi.v3i2.201

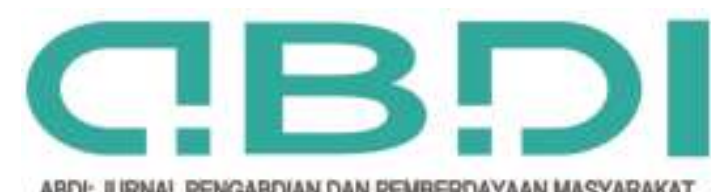

\title{
Pelatihan Pembuatan Kompos dari Sisa Daun Kempaan Gambir di Nagari Koto Baru Korong Nan Ampek
}

\author{
Resti Fevria1, Vauzia Vauzia², Ganda Hijrah Selaras $^{3}$, Edwin Edwin ${ }^{4}$ \\ 1,2,3 Jurusan Biologi, Universitas Negeri Padang \\ ${ }^{4}$ Jurusan Agroekoteknologi, Universitas Andalas Padang \\ E-mail: restifevria@fmipa.unp.ac.id
}

\begin{abstract}
Abstrak
Tanaman gambir (Uncaria gambir Hunte Roxb) adalah komoditas spesifik Lokasi Sumatera Barat. Jumlah petani yang mengusahakan gambir sekitar 125.000 RTP dengan luas garapan 1-2,0 ha/RTP. Sentra penghasil Gambir di Sumatera Barat adalah wilayah Kabupaten Pesisir selatan yaitu Kecamatan Koto XI Tarusan (KBKA) (Nazir, 2000 dan Denian, 2004). Kegiatan ini dilaksanakan diwilayah KBKA. Limbah gambir saat ini tidak termanfaatkan secara optimal. Dalam satu Ha lahan gambir berumur $<3$ tahun dihasilkan $4-5$ ton ampas daun gambir dan jumlah ini meningkat dengan meningkatnya umur tanaman. Pada tanaman yang berumur > dari 3 tahun produksi daun ini bisa mencapai 6-7 ton/ha. Biasanya ampas ini ditaburkan saja dipermukaan tanah tanpa diolah. Ampas kempaan ini perlu diolah menjadi pupuk organik, sehingga kandungan unsur hara didalam pupuk organik meningkat. Disamping itu, sumber daya manusia yang terbatas dalam pengolahan sumber daya alam. Untuk itu perlu diadakan "Pelatihan Pembuatan Kompos dari Limbah daun Gambir di Nagari KBKA Kecamatan Koto XI Tarusan, Pesisir Selatan” Kegiatan yang dilaksanakan adalah pertama Sosialisasi program kepada masyarakat Nagari KBKA dan petani gambir, setelah itu penyusunan rencana kegiatan yaitu dengan memberikan materi pembuatan kompos dari Sisa Kempaan gambir serta teknik pelaksanaannya yang dimulai dengan membuat bak pengolahan berukuran lebar $1 \mathrm{~m}$, panjang 1-2 m dan tinggi $1 \mathrm{~m}$, kemudian membuat kompos sebanyak 1 ton dengan penambahan $250 \mathrm{~kg}$ pupuk kandang, stardec $2,5 \mathrm{~kg}$, kapur dolomit $2,5 \mathrm{~kg}$ dan Urea $2,5 \mathrm{~kg}$. Proses pengomposan berlangsung selama 1 bulan dan dilakukan pengadukkan sekali seminggu. Setelah itu dilaksanakan program pemeliharaan dan rancangan evaluasi.
\end{abstract}

Kata kunci: Ampas gambir, Kompos, KBKA, Pesisir Selatan

Abstract

The gambier plant (Uncaria gambir Hunte Roxb) is a specific commodity for West Sumatra. The number of farmers who cultivate gambier is around 125,000 RTP with a cultivated area of 1-2.0 ha/RTP. The center of Gambir production in West Sumatra is the South Coastal District, namely Koto XI Tarusan (KBKA) District (Nazir, 2000 and Denian, 2004). This activity was carried out in the Nagari KBKA area. Gambier waste is currently not utilized optimally. In one ha of gambier land aged $<3$ years, 4-5 tons of gambier leaf pulp are produced and this amount increases with increasing plant age. In plants aged > 3 years, leaf production can reach 6-7 tons/ha. Usually this waste is just sprinkled on the surface of the soil without being processed. This compressed dregs need to be processed into organic fertilizer, so that the nutrient content in organic fertilizer increases. In addition, limited human resources in the processing of natural resources. For this reason, it is necessary to hold "Compost Making Training from Gambir Leaf Waste in Nagari KBKA Koto XI Tarusan District, Pesisir Selatan" The activities carried out were firstly socializing the program to the Nagari KBKA community and gambir farmers, after that the preparation of an activity plan was by providing materials for making compost from The rest of the gambier compression and its implementation technique begins with making a processing tank measuring $1 \mathrm{~m}$ wide, $1-2 \mathrm{~m}$ long and $1 \mathrm{~m}$ high, then making 1 tonne of compost with the addition of $250 \mathrm{~kg}$ of manure, $2.5 \mathrm{~kg}$ of stardec, dolomite lime 2, $5 \mathrm{~kg}$ and Urea $2.5 \mathrm{~kg}$. The composting process lasts for 1 month and is stirred once a week. After that, a maintenance program and evaluation plan are carried out.

Keywords: Gambir pulp, Compost, KBKA, Pesisir Selatan

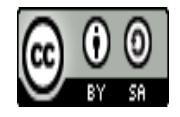

Received: 17 Oktober 2021 Revised: 27 Desember 2021 Available Online: 28 Desember 2021 


\section{Pendahuluan}

Gambir termasuk dalam sepuluh komoditas ekspor utama Provinsi. Ekspor gambir Indonesia lebih dari 80 persen berasal dari Sumatera Barat, dengan negara tujuan ekspor meliputi Australia, Bangladesh, hongkong, India, malaysia, Nepal, Pakistan, Taiwan, Jepang, Saudi Arabia, Filipina, Thailand dan Singapura (Gumbira et al., 2009). Gambir sebagai komoditas ekspor mampu memberikan sumbangan cukup berarti pada produk Domestik Bruto (PDRB) daerah dan devisa Negara (Gumbira, Sa'id, 2008). Prospek pasar dan potensi pengembangan gambir cukup baik karena produk olahannya digunakan sebagai bahan baku dalam berbagai industri. Luas tanam gambir cendrung meningkat dari tahun ke tahun (Badan Pusat Statistik Sumbar, 2013). Pengembangan gambir dalam jangka panjang akan berdampak pada pelestarian lingkungan. Oleh karena itu, aspek ramah lingkungan dan berwawasan bioindustri perlu diperhatikan, sehingga tidak menganggu keberlanjutan usaha dan kelestarian lingkungan dalam jangka panjang.

Pada umumnya masyarakat Nagari Koto Baru Korong Nan Ampek berprofesi sebagai petani, berupa padi dan gambir serta komoditi sampingan lainnya, sedangkan komoditi utamanya adalah gambir (Nazir, 2000). Pelaku pertanian dan perkebunan adalah laki-laki. Jumlah petani yang mengusahakan gambir sekitar 125.000 rumah tangga petani (RTP) dengan luas garapan 1 - 2,0 ha/RTP. Budidaya gambir umumnya secara monokultur pada kawasan perbukitan dan diluar pemukiman penduduk.

Dalam budidaya gambir saat ini tidak termanfaatkan secara secara optimal limbah kempaan daun gambir. Dalam satu hektar lahan gambir berumur $<3$ tahun dihasilkan $4-5$ ton ampas kempaan daun gambir dan jumlah ini meningkat dengan meningkatnya umur tanaman. Pada tanaman yang berumur > 3 tahun produksi daun ini bisa mencapai 6-7 ton/ha. Biasanya ampas kempaan ini ditaburkan saja dipermukaan tanah tanpa diolah sama sekali sehingga manfaatnya untuk tanaman berkurang. Ampas kempaan ini perlu diolah menjadi pupuk organik dengan adanya tambahan pupuk kandang, sehingga kandungan unsur hara dalam pupuk organik ini dapat ditingkatkan.

Permasalahan yang dihadapi masyarakat Nagari KBKA adalah: 1). Setiap kali kempa menggunakan 20 - $25 \mathrm{~kg}$ daun dan menghasilkan gambir kering sebanyak 4-5 kg dan ampas kempaan sebanyak 15 - $20 \mathrm{~kg}$. 2). Untuk satu hektar lahan gambir dengan hasil $800 \mathrm{~kg} / \mathrm{ha}$ diperlukan $200-160$ kali kempa dan menghasilkan 3 - 4 ton/ha ampas kempaan. Ampas kempaan ini oleh petani hanya ditaburkan dipermukaan tanah disekitar rumpun tanaman, sehingga manfaatnya kepada tanaman tidak seberapa. 3). Terbatasnya SDM yang ada dalam pengolahan daun sisa kempaan gambir ini. Masyarakat menginginkan keterampilan yang dapat mendukung pemenuhan kebutuhan sehari-hari dari segi ekonomi.

\section{Metode Pelaksanaan}

Transfer IPTEK yang dilakukan Tim Pelaksana PKM, dilakukan pada tiap tahapan dengan menggunakan prinsip bahwa setiap inovasi yang diterima oleh mitra sebaiknya melalui proses, mendengar, mengetahui, mencoba, mengevaluasi, menerima, meyakini, dan melaksanakan. Melalui proses-proses tersebut diharapkan keterampilan yang diberikan dapat diadopsi secara berkesinambungan dan mandiri ke depannya. Supaya setiap proses berlangsung dengan baik, maka penyampaian keterampilan kepada Mitra ditempuh melalui tahapan penjelasan, diskusi, praktek serta dilakukan tahap pendampingan. Kegiatan PKM Pelatihan Pembuatan Kompos dari Ampas Daun Gambir sisa Kempaan di Nagari Koto Baru Korong Nan Ampek Kecamatan Koto XI Tarusan, Pesisir Selatan dijabarkan sebagai berikut:

\subsection{Sosialisasi Program}

Meskipun Mitra sudah menandatangani kesediaan bekerjasama, karena kegiatan melibatkan petani gambir (masyarakat), maka sosialisasi perlu juga dilakukan terhadap mereka.

\subsection{Rencana Tindakan}

Rincian aktivitas pembinaan perlu disampaikan secara detail pada Mitra, karena setiap langkah pembinaan membutuhkan partisipasi mitra. 


\subsection{Pelaksanaan Kegiatan}

Kegiatan ini dilakukan dengan memberikan materi tentang Pembuatan kompos dari daun sisa kempaan gambir, Manfaat kompos yang digunakan serta bahan yang digunakan. Materi berupa apa yang dimaksud dengan kompos kelebihan dan kekurangan kompos serta teknik pelaksanaannya; yang dimulai dari penyiapan bahan, pembuatan kompos, pengomposan dan pengemasan.

\subsection{Program Pemeliharaan}

Program pemeliharaan perlu dirancang dengan baik, dengan melakukan evaluasi secara periodik kelapangan. Hal ini juga bertujuan untuk membantu jika dalam pelaksanaan secara mandiri terdapat kendala.

\subsection{Partisipasi mitra dalam kegiatan}

Partisipasi mitra dalam kegi atan ini sangat penting, karena bahan dasar dari pembuatan kompos ini yaitu daun sisa kempaan gambir akan disediakan oleh mitra, sebab mitra kegiatan ini adalah petani gambir. Dan pembuatan kompos juga akan dilakukan oleh mitra. Lokasi pembuatan kompos juga pada lokasi mitra dan hasil dari kegiatan ini yaitu kompos yang dihasilkan juga akan dimanfaatkan oleh mitra.

\subsection{Evaluasi program dan Keberlanjutan}

Evaluasi akan dilaksanakan secara berkala untuk melihat keterlaksanaan program dan ketercapaian target kegiatan, diharapkan kegiatan ini akan terus dilanjutkan oleh mitra sebagai solusi dari permasalahan mitra/sehingga tujuan dari kegiatan ini dapat tercapai seperti: keterampilan mengolah sisa kempaan daun gambir menjadi kompos oleh petani gambir, lingkungan menjadi bersih, sehat dan indah serta peningkatan pendapatan petani gambir yang tidak hanya dari gambir saja, tetapi dari kompos sisa kempaan daun gambir juga. Untuk proses pembuatan kompos, penjelasannya dapat dilihat pada gambar 1 .

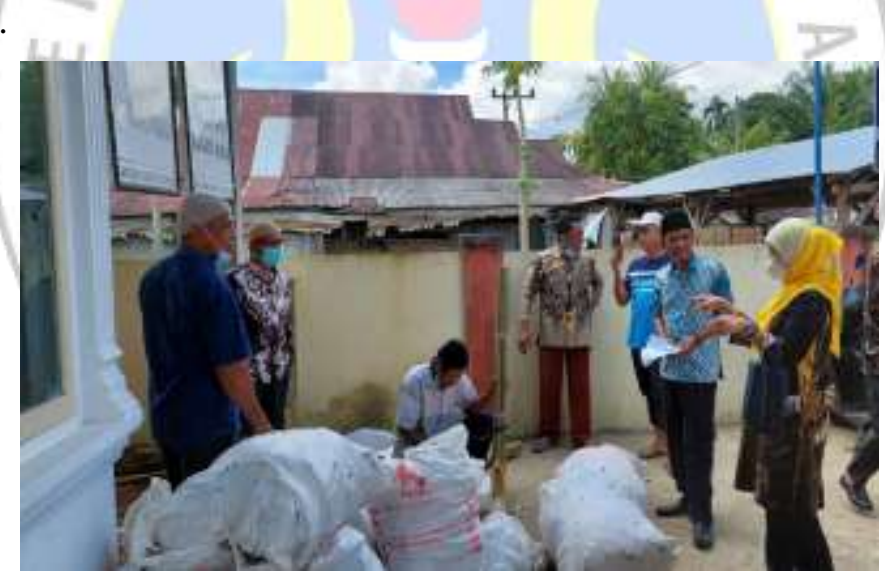

\section{Gambar 1. Penjelasan tentang Pembuatan kompos dari Sisa Kempaan Gambir di Nagari KBKA}

Untuk bahan - bahan yang digunakan dalam pembuatan kompos dapat dilihat pada Tabel 1.

Tabel 1. Komposisi bahan pembuatan kompos dari sisa kempaan gambir

\begin{tabular}{lll}
\hline Bahan & Jumlah & \multicolumn{1}{c}{ Fungsi } \\
\hline Ampas gambir & $1 \mathrm{ton}$ & Bahan dasar \\
Bambu & $1 \times 1 \times 8$ & Untuk membuat bak \\
Plastik Hitam & $1 \mathrm{~m}$ & Untuk alas dan menutup kompos \\
Pupuk Kandang & $50 \mathrm{~kg}$ & Penambah unsur hara \\
Stardec & $500 \mathrm{~g}$ & Bio Aktivator \\
Urea & $500 \mathrm{~g}$ & Penambah unsur N \\
Dolomit & $500 \mathrm{~g}$ & Penetral pH Kompos \\
\hline
\end{tabular}


Dari tabel diatas dapat dilihat bahan-bahan yang digunakan dalam pembuatan kompos dengan bahan dasar Sisa Kempaan Gambir. Pada tabel juga dijelaskan jumlah bahan yang dibutuhkan serta fungsinya.

\section{Hasil dan Pembahasan}

Dari kegiatan yang telah dilaksanakan yaitu Pembuatan kompos dari sisa Kempaan Gambir di Nagari KBKA, Tarusan Pesisir Selatan, didapatkan hasil sebagai berikut:

\subsection{Pembuatan Kompos}

Untuk proses pembuatan kompos dapat dilihat pada Tabel 2.

Tabel 2. Proses Pembuatan Kompos dari Sisa Kempaan Gambir.

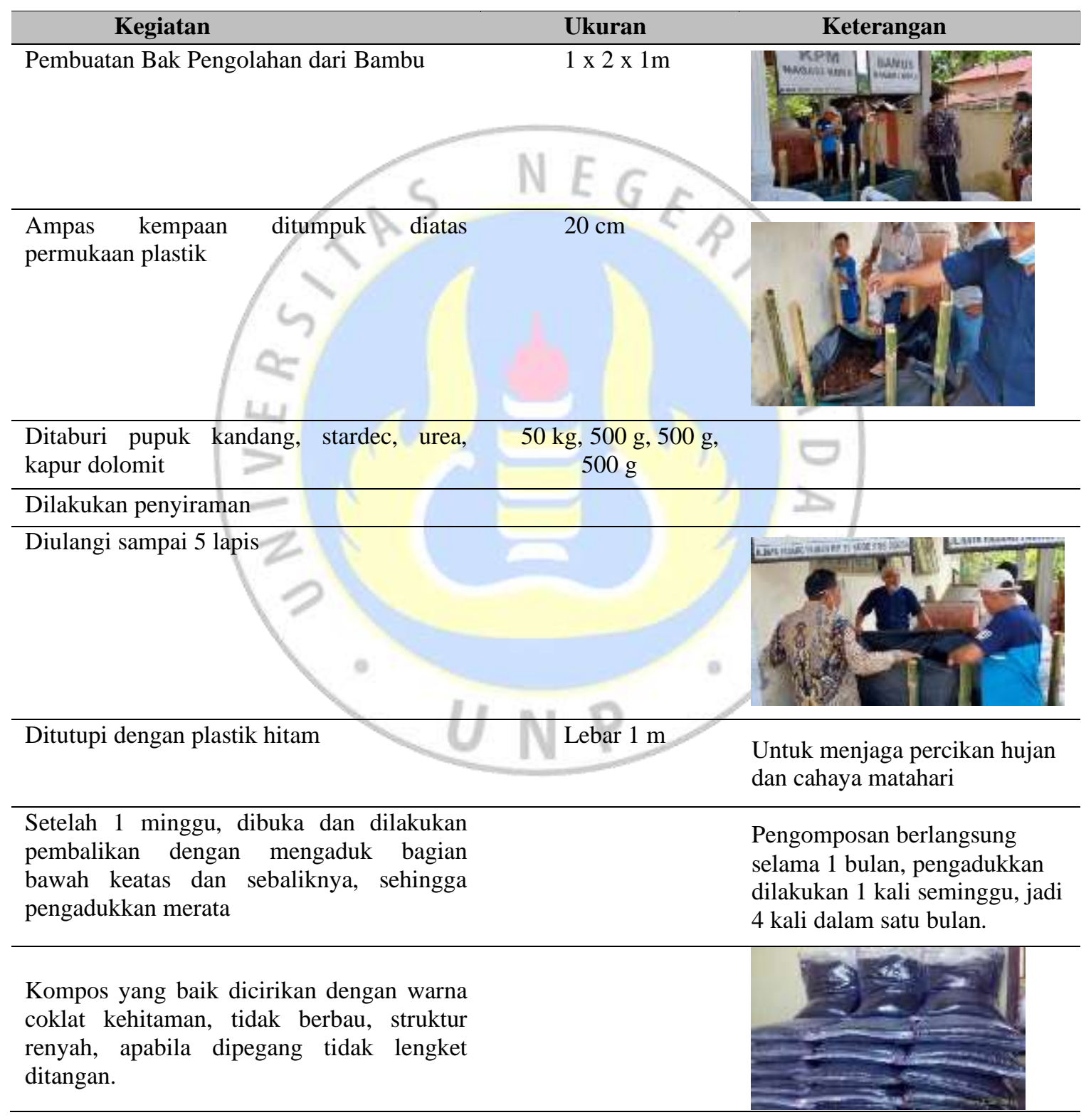

\subsection{Pembahasan}

Pelatihan Pembuatan Kompos dari Limbah daun Gambir di Nagari KBKA Kecamatan Koto XI Tarusan, Pesisir Selatan, ini diberikan kepada petani gambir dan pemuda Nagari KBKA. kegiatan yang dilaksanakan adalah pertama Sosialisasi program kepada masyarakat Nagari KBKA dan petani 
gambir, setelah itu penyusunan rencana kegiatan yaitu dengan memberikan materi pembuatan kompos dari Sisa Kempaan gambir serta teknik pelaksanaannya yang dimulai dengan membuat bak pengolahan berukuran lebar $1 \mathrm{~m}$, panjang 1-2 m dan tinggi $1 \mathrm{~m}$, kemudian membuat kompos sebanyak 1 ton dengan penambahan $250 \mathrm{~kg}$ pupuk kandang, stardec 2,5 kg, kapur dolomit 2,5 $\mathrm{kg}$ dan Urea $2,5 \mathrm{~kg}$. Proses pengomposan berlangsung selama 1 bulan dan dilakukan pengadukkan sekali seminggu. Setelah itu dilaksanakan program pemeliharaan dan rancangan evaluasi. Pupuk kompos merupakan salah satu pupuk organik yang dibuat dengan cara menguraikan sisa-sisa tanaman dan hewan dengan bantuan organisme hidup. Untuk membuat pupuk kompos diperlukan bahan baku berupa material organik dan organisme pengurai. Pengomposan adalah proses dimana bahan organik mengalami penguraian secara biologis, khususnya oleh mikroba-mikroba yang memanfaatkan bahan organik sebagai sumber energi. Membuat kompos adalah mengatur dan mengontrol proses alami tersebut agar kompos dapat terbentuk lebih cepat. Proses ini meliputi membuat campuran bahan yang seimbang, pemberian air yang cukup, pengaturan aerasi, dan penambahan aktivator pengomposan.

Proses pengomposan berlangsung selama empat minggu yang ditandai dengan meningkatnya temperature sampai 700 celcius. Kemudian temperature akan menurun karena mulai berkurangnya proses dekomposisi dan akhirnya mencapai titik konstan, hal ini menunjukkan proses pengomposan sudah selesai. Pupuk kompos menyediakan nutrisi bagi tanaman. Selain itu pupuk kompos bekerja dengan cara memperbaiki struktur fisik, kimia dan biologi tanah. Secara fisik, kompos meningkatkan kemampuan tanah untuk menyimpan air sebagai cadangan di saat kekeringan. Kompos juga membuat tanah menjadi gembur dan cocok sebagai media tumbuh akar tanaman. Pada tanah tipe pasir sekalipun, material kompos berguna menjadi perekat sehingga tanah menjadi lebih solid. Pada tanah liat atau tanah lempung, kompos berfungsi menggemburkan tanah agar tidak terlalu solid. Pupuk kompos yang baik memiliki ciri-ciri umum sebagai berikut: (1) Baunya sama dengan tanah, tidak berbau busuk, (2) Warna coklat kehitaman, berbentuk butiran gembur seperti tanah, (3) Jika dimasukkan ke dalam air seluruhnya tenggelam, dan air tetap jernih tidak berubah warna, (4) Jika diaplikasikan pada tanah tidak memicu tumbuhnya gulma. Setelah kegiatan ini selesai, petani gambir dan pemuda Nagari KBKA dapat mengaplikasikan kegiatan ini secara kontiniu, selain untuk kebutuhan sendiri, kompos yang dihasilkan dapat dijual untuk meningkatkan pendapatan petani dan pemuda Nagari KBKA.

\section{Kesimpulan}

Pada umumnya masyarakat Nagari Koto Baru Korong Nan Ampek berprofesi sebagai petani, berupa padi dan gambir serta komoditi sampingan lainnya, sedangkan komoditi utamanya adalah gambir. Selama ini sisa kempaan gambir di Nagari KBKA belum termanfaatkan, untuk itu dilaksanakan pelatihan pembuatan kompos di Nagari KBKA Tarusan Pesisir Selatan. Agar sisa kempaan gambir. Tujuannya adalah agar sisa kempaan gambir bisa termanfaatkan dan nilai ekonomisnya meningkat. Disamping untuk kebutuhan sendiri kompos yang dihasilkan dari kegiatan ini bisa dijual juga, sehingga bisa meningkatkan pendapatan petani gambir.

\section{Daftar Pustaka}

Badan Pusat Statistik Sumbar. (2013). Sumatera Barat dalam angka tahun 2012. Padang: BPS Sumbar.

Gumbira, Sa'id, E. (2008). Review kajian, penelitian dan pengembangan agroindustri strategis Nasional: Kelapa sawit, kakao dan gambir. Jurnal Teknik Industri Pertanian, 9(1), 45-55.

Gumbira, S., Syamsu, E., Mardiliyati, A., Herryandie, N., Afni, D. ., Rahayu, R. A., \& Aditya, H. (2009). Agroindustri dan Bisnis Gambir Indonesia. Bogor: IPB.

Nazir, N. (2000). Gambir, budidaya, pengolahan, dan prospek diversifikasinya. Padang: Yayasan Hutanku. 